\title{
BIBLIOTECA UNIVERSITÁRIA PROATIVA
}

\author{
Maria de Fátima Pereira Raposo \\ Carmelita do Espírito Santo
}

\section{Resumo}

O trabalho visa apresentar alguns procedimentos que podem caracterizar uma postura proativa em bibliotecas universitárias. Para tanto, apresenta aspectos do conceito de proatividade em um contexto onde o uso e a aplicação das tecnologias de informação (TI) constituem-se ferramentas essenciais para promover a inclusão social/digital no Brasil. O trabalho é abordado no contexto das bibliotecas do Centro Universitário da Cidade do Rio de Janeiro - UNIVER CIDADE. A adoção de procedimentos pró-ativos no Sistema de Bibliotecas da UNIVER CIDADE possibilitou um maior alcance dos problemas de informação de seus usuários, oferecendo, assim, subsídios para uma gestão eficiente da informação. Conseqüentemente, a confiança nos serviços da biblioteca e a participação nos programas instituídos cresceram proporcionalmente às ações pró-ativas adotadas pelo Sistema de Bibliotecas.

\section{Palavras-chave}

Biblioteca universitária; Biblioteca proativa; Gestão da informação.

\section{PRO-ACTIVE UNIVERSITY LIBRARY}

\begin{abstract}
This work aims to present some procedures that characterize a pro-active posture in Brazilian university libraries. For this purpose, aspects of the concept of pro-active libraries are presented in a context where growth in the number of needy students entering private higher education demands ever more use and application of information technology (IT) for their learning processes. This work is developed in the context of the Library System of the Centro Universitário da Cidade do Rio de Janeiro - UNIVER CIDADE. The adoption of pro-active procedures in the UNIVER CIDADE Library System allowed a better reaching of the users' information problems, thus offering support for efficient information management. Consequently, the use of the system's services and the participation in the instituted programs grew as proportionately as the pro-active actions adopted by the Library System were implemented.
\end{abstract}

\section{Key words}

University library; Pro-active library. 


\section{INTRODUÇÃO}

A Universidade e a Biblioteca são instituições sociais voltadas para o atendimento das necessidades da sociedade em geral. Contudo, na sociedade do conhecimento, a biblioteca universitária passa por um momento crucial no que se refere ao seu papel de auxílio e apoio ao processo educacional. De acordo com a Associação Brasileira de Mantenedoras do Ensino Superior - ABMES (2006) o Brasil tem cerca de quatro milhões de estudantes em cursos de graduação, sendo 2.750 .652 no setor privado. Estes números podem refletir os subsídios de programas governamentais brasileiros que visam levar a universidade às classes menos favorecidas, como o programa Universidade para Todos PRO UNI e programa Fundo de Financiamento ao Estudante do Ensino Superior - FIES. O PRO UNI tem como finalidade a concessão de bolsas de estudo integrais e parciais, a estudantes de cursos de graduação e seqüenciais de formação específica, em instituições privadas de educação superior, oferecendo em contrapartida, isenção de alguns tributos àquelas que aderirem ao Programa. O Fundo de Financiamento ao Estudante do Ensino Superior - FIES é um programa do Ministério da Educação - MEC destinado a financiar a graduação no Ensino Superior de estudantes que não têm condições de arcar integralmente com os custos de sua formação.

Este cenário evidencia um paradoxo no sistema educacional brasileiro. De um lado, demonstra que o nível educacional do país está crescendo, mas, por outro lado evidencia o problema da exclusão digital, pois a maioria dos novos alunos ainda tem grande dificuldade para usar e aplicar as tecnologias de informação e comunicação (TICs). Este problema é observado diariamente nas bibliotecas do Sistema de Bibliotecas do Centro Universitário da Cidade do Rio de Janeiro, instituição de ensino superior da rede particular, na qual este trabalho está ambientado.

Nosso objetivo principal é mostrar alguns procedimentos que caracterizam uma postura pró-ativa em bibliotecas universitárias brasileiras. Para tanto, apresenta aspectos do conceito de pró-atividade em um contexto onde o uso e a aplicação das Tecnologias de Informação(TIs) constituem-se em ferramentas essenciais não só para o processo educacional do universitário, mas também para ajudar na promoção da inclusão social/digital no Brasil.

Em nossa abordagem, a missão das instituições de ensino superior deve ultrapassar o contexto universitário. Assim, devem incluir em suas rotinas programas e/ou atividades que possam dar aos 
seus usuários a devida competência informacional "Information Literacy” para resolver os seus problemas de informação em qualquer fase de suas vidas.

\section{SISTEMA DE BIBLIOTECAS DA UNIVERCIDADE}

O Sistema de Bibliotecas tem como objetivo principal assegurar infra-estrutura de informação aos programas de ensino, pesquisa e extensão da Univercidade.

O acervo bibliográfico do Sistema de Bibliotecas da Univercidade, com aproximadamente 400.000 volumes, é composto de livros, publicações periódicas (impressos e eletrônicos), monografias de conclusão de curso, CD-Rom, DVD, disquetes, fitas de vídeo, fitas cassete, mapas, slides e discos, distribuído nas diferentes bibliotecas das unidades (RAPOSO, ESPÍRITO SANTO E UNGER, 2005).

Além do acervo prioritário para os universitários, há um outro acervo dedicado ao Ensino Fundamental e Médio, organizado nas Bibliotecas do Colégio Cidade. Possui também Coleções Especiais como o acervo dos Juristas Clóvis Beviláqua e Vicente Sobrinho Porto, parte da coleção de livros do Jornalista Paulo Francis e do Filólogo Otávio de Brito, a série Brasiliana, acervo russo sobre cultura, arte e literatura, entre outras. Faz parte também do acervo do sistema de Bibliotecas da UniverCidade, o arquivo particular do jornalista e colunista social Ibraim Sued, composto de matérias publicadas em jornais e revistas e objetos pessoais. Para tratamento e recuperação de informações do acervo foi implantada uma única base de dados para todas as bibliotecas da UniverCidade utilizando-se o sistema Argonauta, tanto a nível local, como remotamente, através da Web.

Entre os serviços oferecidos no Sistema de Bibliotecas da UniverCidade, destacam-se: acesso às base de dados on-line, consulta a bases de dados especializadas, (entre as unidades ou entre as bibliotecas de IES’s do Rio de Janeiro), comutação bibliográfica, levantamento bibliográfico, acesso à Internet, treinamento de usuários, entre outros. Além desses, oferece os recursos de compartilhamento através de sua participação nas seguintes redes:

COMUT - Comutação Bibliográfica, como Biblioteca Solicitante; 
REDARTE - Rede de Bibliotecas e Centros de Informação em Arte, Compartilhamento entre Bibliotecas das IES do Estado do Rio de Janeiro;

GIDJ/RJ - Grupo de Profissionais em Informação e Documentação Jurídica do Rio de Janeiro;

APCIS - Associação de Profissionais de Informação em Saúde, que congrega bibliotecários de instituições públicas e privadas tanto acadêmicas como de pesquisa na área de saúde;

CBBU - Comissão Brasileira de Bibliotecas Universitárias, da qual a Diretora Geral de Bibliotecas é Conselheira Regional para a Região Sudeste II (RJ).

\section{CENÁRIO PARA A CONSTRUÇÃO DA PROATIVIDADE}

A Informação sempre foi importante nas universidades, mas agora parece ter assumido importância ainda maior que no passado, pois já foi chamada de sangue que dá vida às universidades, e considerada como parte da própria infra-estrutura da universidade. Na atualidade, podemos dizer que os conceitos informação e universidade são indissociáveis, pois a informação ocupa lugar central em todas as rotinas universitárias. "Tão central que se confundiria com a própria noção de universidade.” (MUELLER, 2000).

As Instituições de Ensino Superior - IES's de todo o mundo estão reavaliando suas formas de reunir, processar e disseminar informações para o ensino, pesquisa, extensão e para sua própria administração. Neste contexto, as bibliotecas universitárias desempenham um papel crucial, pois a biblioteca universitária pode ser considerada como o espelho da universidade. A qualidade dos serviços oferecidos na biblioteca universitária pode ser um fator de determinação da qualidade dos serviços oferecidos na universidade como um todo. Assim, para fazer jus ao seu papel de espelho da universidade, a biblioteca deve estar sempre atenta para responder com qualidade as demandas informacionais de seus clientes além de, muitas vezes, se adiantar e prover essa demanda.

Sabemos que com o surgimento da Internet, a instantaneidade, a efemeridade, a complexidade e a rapidez com que as informações se processam e veiculam na rede, dificultam o controle e a qualidade da informação (ESPÍRITO SANTO, 2004). Assim, a sobrevivência da biblioteca e de suas atividades de apoio ao ensino e à pesquisa depende de uma postura estratégica do gestor da informação, o que implica na percepção, avaliação e adoção de perspectivas diferenciadas para a 
administração no panorama atual. Implica dizer aqui que saber como acessar e utilizar a informação, representa um elemento essencial na educação moderna, o que dá ao trabalho educativo, o papel de protagonista na construção de uma sociedade emancipadora e igualitária. Entretanto, as competências necessárias para localizar, processar e utilizar a informação, não acompanha as tendências das “infovias” ou "supervias” da chamada Sociedade da Informação (BELLUZZO, 2006). Isto é observado na rotina da maioria das bibliotecas universitárias brasileiras, em especial nas bibliotecas do Sistema de Bibliotecas da UniverCidade. Para se ter uma noção da questão, uma boa parcela dos alunos não sabem, ao menos, o que é uma biblioteca, pois nunca foram apresentados a ela. Seguem-se ainda problemas comuns na maioria das nossas bibliotecas enfrentados pelos alunos que:

a. não sabem utilizar o computador devidamente para fazerem suas pesquisas;

b. não sabem fazer pesquisas para realizarem seus trabalhos acadêmicos (freqüentemente copiam textos);

c. não dispõem de um ambiente próprio para estudar fora da universidade (para concursos públicos, por exemplo);

d. moram em lugares, aonde não existem bibliotecas.

Diante destes problemas o Sistema de Bibliotecas elaborou alguns projetos, hoje transformados em programas, que visam manter a postura proativa do sistema mediante as necessidades de informação de seus usuários: programa de treinamento de usuários; competência informacional; complemente sua formação geral e programa educação continuada dos bibliotecários, entre outros.

Para avaliar o alcance destes programas, inserimos aqui o conceito de biblioteca pró-ativa, cuja finalidade principal está em oferecer serviços que ultrapassem os modelos tradicionais de atendimento ao usuário. É oportuno saber como este conceito pode ser aplicado na biblioteca universitária.

\section{PROATIVIDADE BIBLIOTECÁRIA NA UNIVERCIDADE}

Um dos significados do prefixo "pró" é antecipação, algo que acontece antes. Neste contexto, a pessoa proativa está sempre se antecipando aos acontecimentos, fazendo até mesmo alguma espécie 
de previsão para poder atuar de uma determinada forma planejada. Neste caso, é necessária uma análise do contexto, a identificação e a seleção de alternativas que possam levar à previsão dos resultados de cada cenário. É claro que isto leva algum tempo, mas, com um bom planejamento, há chances de sucesso (LAGO, 2005).

Então ser proativo significa tomar a iniciativa. Embora a iniciativa faça parte da proatividade, ela se apresenta apenas como uma reação e não como uma ação para responder uma determinada demanda. A proatividade se efetiva quando, além do planejamento, se adiciona a uma determinada demanda um questionamento positivo do processo, conforme exemplo abaixo:

Um instrutor, dando uma palestra, pergunta quem poderia tirar cópias xerox de um artigo. Alguém rapidamente se oferece como voluntário. A pessoa proativa se oferece como voluntária e também sugere algo do tipo: "Podemos escanear o artigo?" ou "Que tal pedirmos para alguém colocar o artigo no formato word ou Power Point?" Trata-se de um questionamento visando a melhoria do processo ou do resultado. Neste sentido, um questionamento positivo é a base para toda mudança que pode ocorrer em um determinado setor de atividade, que pode levar a mudanças de maneira consistente. Assim, "somando-se a iniciativa + planejamento + questionamento positivo tem-se a proatividade. Quando acrescida da criatividade, a pró-atividade pode levar à inovação”. Criatividade sem proatividade não passa de um monte de idéias que podem ser ou não ser úteis. Proatividade sem criatividade resultará em mudança de pouco ou curto impacto(LAGO, 2005).

Neste contexto, o sentido do conceito de proatividade revela que há uma pré-disposição pessoal para iniciar e manter ações que alteram diretamente o ambiente. Um termo bastante recorrente nesta questão é o interacionismo, onde a abordagem proativa considera as possibilidades de indivíduos criarem seus ambientes. A compreensão da abordagem interacionista conduz a processos específicos, tais como seleção, reestruturação cognitiva, evocação e a manipulação, que envolve esforços intencionais das pessoas em moldar, alterar, explorar e mudar seu ambiente social. Através destes processos, é possível alterar intencionalmente situações, sejam elas sociais ou nãosociais(POZZEBON, 1998).

Por outro lado, há conflitos em relação ao conceito de proatividade, pois muitos que crêem serem proativos, na maioria das vezes, confundem o conceito, pois acham que ser proativo é ter iniciativa, outras pessoas, contudo, entendem que o termo significa ter orientação para a ação rápida. A 
pessoa proativa está sempre se antecipando aos acontecimentos, fazendo até mesmo alguma espécie de previsão para poder atuar de uma forma planejada.

Para o sistema de Bibliotecas da Universidade, o conceito de proatividade está intrinsecamente relacionado com as rotinas bibliotecárias. Como já mencionado, o principal problema enfrentado pela maioria das bibliotecas da UniverCidade é a dificuldade que a maioria dos alunos enfrentam para utilizar os recursos informacionais (TI) disponíveis na biblioteca para a realização de suas pesquisa e trabalhos acadêmicos. Ser proativo, neste sentido implica na adoção de medidas que possam ajudar ao aluno a resolver seus problemas de informação. Isto requer a colaboração e cooperação não só da biblioteca, mas de diversos setores da universidade. Implica falar aqui em negociação e articulação entre os diversos setores da Universidade, como a coordenação acadêmica, professores, setor administrativo, setor de informática, etc. Além disso, o bibliotecário universitário deve ser um profissional capacitado para responder à demanda das necessidades de suas respectivas bibliotecas, o que implica no constante aperfeiçoamento e atualização de seus conhecimentos bibliotecários. É neste contexto que inserimos os procedimentos proativos que vêm sendo aplicados no Sistema de Bibliotecas da UniverCidade.

\section{PROGRAMA DE TREINAMENTO DE USUÁRIOS}

O objetivo do programa de treinamento de usuários, aplicado pelos bibliotecários, é mostrar ao aluno/usuário como a biblioteca funciona e como utilizar os seus serviços. O programa engloba tópicos como organização do acervo, comportamento e serviços oferecidos. O programa é oferecido e aplicado pelos bibliotecários (RAPOSO, ESPÍRITO SANTO e UNGER, 2005). O projeto aborda os seguintes tópicos:

o Conduta: diz respeito a apresentação das normas de comportamento no interior da biblioteca com o propósito de mostrar ao aluno que este item influencia bastante na qualidade dos serviços por ela oferecidos.

o Preservação do acervo: aborda as questões relacionadas ao manuseio do material do acervo objetivando a conscientização quanto à preservação do acervo. Os alunos são alertados em relação a problemas como colagem nos livros, anotações, grifos 
com canetas lumicolor, livros rasgados, furtos e outros problemas comumente observados na biblioteca.

o Composição do acervo: neste tópico, o usuário é informado sobre os vários tipos de documentos que compõem o acervo da biblioteca, destacando as especificidades de obras de referência, normas técnicas, códigos, entre outros materiais de uso restrito na biblioteca.

o Catálogo eletrônico: objetiva mostrar ao aluno que o catálogo é o canal de comunicação entre o usuário e o acervo. Neste sentido, são mostrados os tipos de catálogos existentes na biblioteca (local e Internet). É apresentado também um pequeno resumo sobre a organização do acervo, destacando o sistema de classificação adotado (CDD/Cutter).

o Biblioteca virtual: são apresentadas as principais características das bibliotecas tradicionais e das bibliotecas virtuais, exemplificadas através da página da biblioteca no site da UniverCidade (periódicos eletrônicos).

o Serviços oferecidos: este item diz respeito único e exclusivamente aos serviços que a Biblioteca oferece aos seus usuários, conforme já mencionados acima, consulta orientada ao acervo, reserva de livros, empréstimo, empréstimo entre bibliotecas da instituição, empréstimo entre instituições, normalização de trabalhos científicos e técnicos, serviço de comutação bibliográfica, acesso às bases de dados eletrônicas, etc.

o Internet: O objetivo deste tópico é mostrar que embora a Internet seja primordial para o desenvolvimento acadêmico e profissional do usuário, o bom uso da rede depende de uma série de fatores, que engloba, entre outros a qualidade da informação. São apresentados alguns exemplos de busca e recuperação na Internet através do Google e da página da biblioteca no site da UniverCidade.

o E-mail institucional: O aluno regularmente matriculado na UniverCidade recebe um e-mail institucional. É o e-mail que possibilita receber toda espécie de comunicados 
que a instituição produz. No que se refere à biblioteca o e-mail institucional é utilizado como canal direto entre a biblioteca e o aluno. Por este canal, é possível fazer pedidos de devolução de livros atrasados, fazer reservas de livros, informar ao aluno sobre a chegada de livros solicitados para outras unidades, além de outros serviços. O usuário também pode utilizar este serviço para fazer reclamações e dar sugestões não só para a biblioteca na qual ele está inscrito, como também para a DGB - Diretoria Geral de Bibliotecas.

o Normalização: visa dar orientação ao aluno sobre o uso e aplicação das normas da ABNT (NBR 14724 - apresentação de trabalhos acadêmicos, NBR 6023 referências bibliográficas). $\mathrm{O}$ atendimento é feito individualmente ou em grupo.

\section{COMPETÊNCIA INFORMACIONAL NA UNIVERCIDADE}

A idéia de “Information Literacy” emerge com o advento das TICs no início dos anos 70 e atualmente, está associada com práticas de informação e o pensamento crítico, no ambiente das tecnologias de informação e comunicação. O início do movimento foi uma reação de bibliotecários, no sentido de adotar uma posição pro ativa da biblioteca, em relação à crescente demanda por mudanças para inserção na sociedade da informação.

Conforme o Colóquio Competência Informacional e Aprendizado ao longo da vida realizado na Biblioteca de Alexandria em 2005, a competência informacional e o aprendizado ao longo da vida são os faróis da Sociedade, iluminando os caminhos para o desenvolvimento, a prosperidade e a liberdade.

\footnotetext{
“A competência informacional está no cerne do aprendizado ao longo da vida. Ele capacita as pessoas em todos os caminhos da vida para buscar, avaliar, usar e criar a informação de forma efetiva para atingir suas metas pessoais, sociais, ocupacionais e educacionais. É um direito humano básico em um mundo digital e promove a inclusão social em todas as nações. $\mathrm{O}$ aprendizado de toda a vida prepara os indivíduos, as comunidades, e as nações a atingir suas metas e a aproveitar as oportunidades que surgem no ambiente global em evolução para um benefício compartilhado. Auxilia-os e suas instituições a enfrentar os desafios tecnológicos, econômicos e sociais, para reverter à desvantagem e incrementar o bem estar de todos”.(IFLA, 2006).
}

De acordo com o Livro Verde da Sociedade da Informação no Brasil, inclusão digital refere-se não só a aquisição de habilidades básicas para o uso de computadores e da Internet, mas também a 
capacitação para utilização dessas mídias, em favor dos interesses e necessidades individuais e comunitários, com responsabilidade e senso de cidadania.

Para que as pessoas adquiram “information literacy”, é preciso que a educação insira esse aprendizado nos seus currículos. Os elementos necessários para inclusão devem contemplar não só o acesso físico as TICs, mas também a capacitação das pessoas para utilizá-las (BELLUZZO, 2006). A Competência em Informação pode ser desenvolvida sob diferentes concepções baseadas:

o nas tecnologias da informação;

o em fontes de informação;

o na informação como processo;

O na construção do conhecimento;

o na extensão do conhecimento;

o no saber.

O Sistema de Bibliotecas da Univercidade adota a concepção baseada em fontes de informação visando capacitar aos seus usuários para acessá-las de forma independente. As primeiras experiências ocorreram em 2003 na área de Ciências da saúde. Desde aquela data, o trabalho vem sendo criteriosamente avaliado visando o seu aprimoramento para a adequação às necessidades dos alunos. O enfoque metodológico da disciplina propõe:

o contextualizar a informação na sociedade da informação para demonstrar a sua importância na vida acadêmica e profissional dos alunos;

o possibilitar ao aluno o conhecimento dos critérios que determinam a qualidade da informação;

o possibilitar ao aluno o conhecimento de fontes de informação;

o possibilitar ao aluno o conhecimento dos critérios que determinam a qualidade das fontes de informação;

o possibilitar ao aluno o conhecimento das normas de padronização da informação nos mais diversos formatos.

As primeiras experiências ocorreram em 2003 na área de Ciências da saúde. Desde aquela data, o trabalho vem sendo criteriosamente avaliado visando o seu aprimoramento para a adequação às necessidades dos alunos. Atualmente está sendo aplicado na disciplina Trabalho de Conclusão de 
Curso, na qual os alunos estão elaborando projetos de monografias. Está em fase de implantação um projeto, utilizando modelo utilizado na área de saúde, para a área de Ciências Jurídicas. "Pessoas treinadas para a utilização de fontes de informação podem ser chamadas de "competentes em informação.”(ZURKOWSKI, apud DUDZIAK, 2003).

\section{PROGRAMA COMPLEMENTE SUA FORMAÇÃO GERAL}

Este programa foi adotado visando a oferecer aos alunos o acompanhamento dos fatos recentes de informação geral. Para tanto se efetiva através de consultas e leituras a jornais e revistas on-line de informação geral. A leitura desses periódicos poderia ser melhor aproveitada se fossem consideradas as seções que nem sempre são manchetes tais como Educação, Arte, Filosofia, Globalização, Responsabilidade social, Ecologia e Cidadania, etc. Assim, o Sistema de Bibliotecas criou um tipo de “clipping” sobre os assuntos citados. As notícias, veiculadas em periódicos de grande circulação on-line, são selecionadas, indexadas e distribuídas às bibliotecas de cada Unidade. O aluno tem, então, notícias selecionadas à sua disposição, podendo consultá-las facilmente ou copiá-las para leitura posterior. Esse serviço é monitorado pelos professores, em sala de aula, o que motiva os alunos na busca à informação mais detalhada e bastante atualizada, contribuindo assim para a criação do hábito de leitura e para a sua formação geral.

\section{EDUCAÇÃO CONTINUADA DOS BIBLIOTECÁRIOS}

O programa foi implementado com o objetivo de aperfeiçoar e atualizar o conhecimento dos bibliotecários do Sistema de Bibliotecas da Univercidade (RAPOSO e ESPIRITO SANTO, 2006). O programa é desenvolvido em duas categorias:
o técnico;
o interatividade bibliotecária.

No primeiro grupo, estão incluídos todos os elementos que possibilitem o aperfeiçoamento técnico que a profissão bibliotecária exige. Aqui, englobam-se cursos e eventos voltados para a capacitação e/ou atualização sobre as ferramentas utilizadas nas rotinas bibliotecárias. O quesito interatividade bibliotecária está direcionado basicamente para promover o encontro entre os bibliotecários do Sistema. Para tanto, se efetiva através da divulgação e realização de eventos da área de 
biblioteconomia. As notícias sobre eventos e cursos são repassadas pela Intranet a todas as bibliotecas. Os encontros entre os bibliotecários do Sistema ocorrem mensalmente na sede da UniverCidade. Na ocasião, bibliotecários de cada unidade expõem os problemas e conflitos ocorridos durante o mês para serem discutidos e solucionados entre todos em "mesa redonda”. O encontro mensal é reservado também para a leitura de textos atuais da área, que são debatidos visando a aplicação dos conceitos nas bibliotecas. Anualmente é realizado um evento que congrega todas as equipes do Sistema de Bibliotecas do Centro Universitário da Cidade do Rio de Janeiro. Nessa ocasião os funcionários que desenvolveram trabalhos científicos ou práticos têm a oportunidade de expor para toda a comunidade da instituição a sua produção ao longo do ano.

\section{CONCLUSÃO}

Os subsídios dos programas educacionais colaboraram com o aumento de inserção de alunos carentes no ensino superior privado. Entretanto, a maioria desses alunos tem dificuldades para usar e aplicar as tecnologias de informação no seu processo de aprendizado universitário. Este cenário se refletiu no Sistema de Bibliotecas do Centro Universitário da Cidade do Rio de Janeiro - UNIVER CIDADE, que começou a adotar uma postura proativa frente à nova demanda. Os procedimentos utilizados dizem respeito não só ao treinamento para a promoção da competência informacional dos usuários do Sistema, mas também ao corpo de bibliotecários da instituição.

As atitudes proativas do Sistema de Bibliotecas da UniverCidade tornaram possível um envolvimento maior na vida acadêmica trazendo visibilidade às atividades de documentação e informação na instituição e fora dela. O trabalho criterioso e sério é visto pela comunidade acadêmica como modelo de aplicação a ser seguido, pois os resultados, conseguidos com esforço e dedicação, tornam a biblioteca forte componente da estrutura acadêmica e da sedimentação do ensino.

Finalmente, uma administração biblioteconômica que busca a proatividade nas rotinas bibliotecárias contribui para a formação de bons profissionais com perfil adequado ao desempenho das suas variadas funções. As iniciativas vêm repercutindo favoravelmente não só em relação ao profissional bibliotecário, como também do ponto de vista da visibilidade e conceito profissional do Sistema de Bibliotecas. 


\section{BIBLIOGRAFIA}

ABMES. Perfil das IES particulares e sua contribuição para o desenvolvimento do país. Disponível em <http://www.portalmec.gov.br/arquivos/pdf/abmes.pdf.> Acesso em: 16 jan. 2006.

BELLUZZO, R. C. B. Competência em Informação: um diferencial das pessoas na sociedade contemporânea. São Paulo, 2006. Oficina de trabalho.

BRUCE, C. Seven faces of information literacy in higher education. 1997. Disponível em: <http://sky.fit.qut.edu.au/ bruce/inflit/faces/faces1.htm> Acesso em: 13 abr. 2005.

DECLARAÇÃO de Alexandria sobre competência informacional e aprendizado ao longo da vida. Disponível em <http://www.ifla.org/III/wsis/BeaconInfSoc-pt.html> Acesso em: 11 abr. 2006.

DUDZIAK, E. A. Information literacy: princípios, filosofia e prática. Ciência da Informação, v. 32, 2003. Disponível em: <www.ibict.br/cienciadainformação> Acesso em: 19 dez. 2005.

ESPÍRITO SANTO, C. “Quissamã somos nós”: Recursos informacionais para construção de hipertexto sobre identidade cultural. Morpheus, v. 5, 2004 . Disponível em <http://www.unirio.br/morpheusonline/carmelita_do_espirito_santo.htm> Acesso em: 28 nov. 2005.

FIES - Programa de Financiamento Estudantil. Instituições de Ensino. Disponível em: <www3.caixa.gov.br/fies/> . Acesso em: 18 abr. 2006.

FREIRE, I. M. O desafio da inclusão digital. Transinformação, v. 16, p.189-194, 2004.

LAGO, A. O que é pró-atividade? Disponível em <http://www.widebiz.com.br/gente/alfredo/oqeproatividade.html.> Acesso em: 22 set. 2005.

MUELLER, S. P. M. Universidade e informação: a biblioteca universitária e os programas de educação a distância: uma questão ainda não resolvida. DataGramaZero - Revista de Ciência da 
Informação - v. 1, 2000. Disponível em: <http://www.dgz.org.br/ago00/Art_01.Htm> Acesso em: 22 out. 2005.

POZZEBON, M. Um Modelo de EIS que Identifica Características para Comportamentos Proativos na Recuperação de Informação. Dissertação (Mestrado PPGA) - Porto Alegre: UFRGS, 1998.

PROUNI - Programa Universidade para Todos. Disponível em: <prouni.mec.gov.br/prouni> Acesso em: 18 abr. 2006.

RAPOSO, M. F. P.; ESPIRITO SANTO, C. A proactive university library in the Brazilian context. In: ANNUAL CONFERENCE ON INTERNATIONAL ASSOCIATION OF TECHNOGICAL UNIVERSITY LIBRARY, 27., 2006, Porto, Portugal. Embedding Libraries in Learning and Research. Porto: Universidade do Porto, 2006. Disponível em: $<$ http://paginas.fe.up.pt/ iatu2006/authors4.html>. Acesso em: 22/06/2006

RAPOSO M. F. P., ESPÍRITO SANTO C., UNGER R. J. G. Aplicação do conceito de proatividade no sistema de bibliotecas da univercidade. BIBLIOCIDADE, 8., 2005, Rio de Janeiro. Rio de Janeiro: UNIVERCIDADE, 2005.

UNIVERCIDADE: obsessão pela qualidade. Disponível em: <http://www.univercidade.br> Acesso em: 18 abr. 2006. 


\section{Maria de Fátima Pereira Raposo}

Diretora do Sistema de Bibliotecas do Centro Universitário da Cidade do rio de Janeiro. fatima@univercidade.br

\section{Carmelita do Espírito Santo}

Bibliotecária do Centro Universitário da Cidade do rio de Janeiro.

csanto@univercidade.br

Recebido em: 12/05/2006

Aceito para publicação em: jun. 2006 